\title{
Depressive Symptoms in Spouses of HIV Infected Individuals: A Study of HIV Uninfected Caregivers in Pune, India
}

\author{
Manisha V. Ghate ${ }^{*}$, Thomas D. Marcotte ${ }^{2}$, Hrishikesh D. Rangnekar ${ }^{3}$, Rachel Meyer ${ }^{2}$, \\ Maiko Sakamoto², Sanjay M. Mehendale ${ }^{4}$ \\ ${ }^{1}$ National AIDS Research Institute, Pune, India \\ ${ }^{2}$ HIV Neurobehavioral Research Program, UCSD, San Diego, USA \\ ${ }^{3}$ Biosensors International Limited, Pune, India \\ ${ }^{4}$ National Institute of Epidemiology, Chennai, India \\ Email: "mghate@nariindia.org
}

Received 8 October 2014; revised 15 November 2014; accepted 25 November 2014

Academic Editor: Gjumrakch Aliev, University of Atlanta, USA

Copyright (C) 2015 by authors and Scientific Research Publishing Inc.

This work is licensed under the Creative Commons Attribution International License (CC BY).

http://creativecommons.org/licenses/by/4.0/

(c) (i) Open Access

\section{Abstract}

Background: HIV infected individuals are at increased risk of developing psychiatric co-morbidities, particularly depression. Coping with a disease associated with significant morbidity, mortality and financial stress is likely to result in psychiatric morbidity even among caregivers, especially family members. However, there is scarcity of such data in HIV uninfected caregiver spouses. Material and Methods: Beck Depression Inventory (BDI-II), a diagnostic tool that measures depressive symptoms, was administered to HIV uninfected caregiver spouses of HIV infected individuals $(n=55)$ and HIV seronegative individuals from general population $(n=63)$ with similar demographic profile. Chi-square test was used for categorical data. Results: Caregiver spouses exhibited higher depressive symptoms on the BDI-II (mean score 5.25 vs. $3.03 ; p=0.029$ ) as compared to others. The scores tended to be higher on the majority of the items, with sadness $(p=0.032)$, punishment feeling $(p=0.024)$ and crying $(p=0.037)$ being statistically significant. Conclusions: Our results indicate that it is important to address the mental health needs of the spouses of HIV infected individuals as they may play a major role in their care and support in the Indian context.

\section{Keywords}

\section{HIV, Spouses, Depression}

\footnotetext{
${ }^{*}$ Corresponding author.
} 


\section{Introduction}

Psychological impact and psychiatric morbidity associated with HIV infection have received considerable attention in the last decade due to their effect on an individual's personal, sexual, occupational and social life [1]. Depression is the commonest psychiatric condition reported in studies among HIV infected individuals [2]-[4]. The prevalence of major depression in HIV-positive population is nearly two times higher compared to that in healthy people representing the community [5]. A study from India has reported depression in 40\% HIV infected individuals soon after being tested for HIV [6]. Some studies have reported that depression was one of the significant factors for non adherence to antiretroviral treatment [7] [8]. The prevalence and nature of depression in HIV infected individuals have been mentioned in various studies but there is limited literature addressing depression among HIV uninfected caregivers [9]-[15]. To the best of our knowledge, no studies have reported depressive symptoms in HIV uninfected caregivers in India.

Our experience from HIV sero-discordant couple studies [data unpublished] in Pune, India, indicate that majority of the spouses of HIV infected individuals continue to provide support to their partners. The physical and emotional burden faced by the uninfected spouses while supporting their infected partners was likely to lead to some level of psychiatric morbidity, especially depression among them.

The majority of studies evaluating HIV negative caregivers' emotional status have been conducted in western cultures, and there is a scarcity of data on mental health among HIV uninfected caregiver spouses in Indian context.

The Beck Depression Inventory (BDI) is a diagnostic tool that measures depressive symptoms in a variety of settings. Studies have been conducted in developed and developing countries using BDI in adolescents, postpartum women, relatives of critically ill patients and HIV infected individuals [7] [8] [16]-[19]. In this paper, we report the level of depression as measured by BDI-II in HIV uninfected spouses of HIV infected individuals and compared their scores with those of demographically similar HIV uninfected individuals from the general community.

\section{Material and Methods}

\subsection{The Parent Study}

In collaboration with HIV Neurobehavioral Research Programme (HNRP), University of California, San Diego, USA, a prospective study titled "Neuro AIDS in India" was completed at the National AIDS Research Institute, Pune between September 2008 and May 2013 that aimed at adapting the battery of tests for neuro-cognitive function to Indian population, assessing the prevalence of HIV associated neurocognitive disorders (HAND) and estimating the impact of treatment. This study was approved by the Ethics Committees of the HIV Neurobehavioral Research Programme \& National AIDS Research Institute.

All participants were above 18 years of age and gave their written informed consent prior to study participation. Those with active physical illnesses and significant substance or alcohol misuse were excluded from the study. Demographic data was collected on structured questionnaire.

\subsection{Current Study Participants}

Of 286 HIV negative participants enrolled in the study, 55 were living with their HIV positive spouses and were categorized as "HIV uninfected caregiver spouses". The comparison group was drawn from the remaining 231 HIV uninfected individuals, which included 63 participants with similar demographic characteristics (age, gender, education, and employment). Demographic data was collected on a structured questionnaire. As part of their enrollment, participants completed data on socio-demographic profile, depressive symptoms and BDI-II scores.

\subsection{Assessment of Depression}

The Beck Depression Inventory II (BDI-II) [Beck et al. 1996] [20], which has shown high validity and reliability, was used to assess the prevalence and severity of depressive symptoms among the study participants. The BDI-II focuses on both the non-somatic symptoms (e.g. pessimism and diminished self-esteem), and the somatic symptoms (e.g. loss of sexual pleasure and weight loss). Participants were requested to rate 21 items in the tool 
from zero to three according to how they had felt during the previous 2 weeks. The total scores as well as fast screen (FS; Beck et al., 2000) [21], based on non-somatic symptoms, were calculated based on the responses of the participants.

\subsection{Statistical Analysis}

In order to determine the prevalence of depressive complaints, the data on BDI-II was converted into binary variables. Score zero was coded as zero and any of the scores ranging from 1 to 3 was coded as one. Thus, ignoring the intensity, any non-zero score was counted as one. The score 0 indicated that no symptoms were present/ best possible response and 1 indicated some degree of depressive symptomatology. Distribution of all continuous variables was compared using t-tests if normally distributed and the Mann Whitney U Test if distribution was non-normal. The chi-square test was used for categorical data. Results were considered statistically significant with a $p$ value of $<0.05$. Data was analyzed using SPSS (version 14.0, SPSS Inc., USA).

\section{Results}

\subsection{Demographic Characteristics}

Mean age of HIV uninfected caregiver spouses and other HIV uninfected participants was 34.27 years (SD 7.41) and 33.16 years (SD 6.23) respectively. There was no statistically significant difference in the two groups with respect to their age, gender, education and employment (Table 1).

\subsection{Depressive Symptoms}

The mean BDI-II total score was 5.25 (SD 6.42) in the HIV negative caregivers spouses and 3.03 (SD 4.36) in the HIV uninfected participants, showing statistically significant differences $(p=0.029)$ between the two groups (Table 1). Using the cut point of $>13$ as an indicator of at least mild depression [20] (based upon recommendations for western cultures), $12.7 \%$ of the caregivers were classified as having mild depression, compared to $4.8 \%$ of the comparison group $(p=0.12)$.

The BDI-II subscale scores were then analyzed for differences on individual symptoms of depression (Table 2). HIV uninfected caregiver spouses were significantly more likely to have feeling of sadness $(p=0.032)$, crying $(p=0.037)$, and punishment feeling $(p=0.024)$ compared to HIV uninfected participants. Additionally, there was borderline significance $(p<0.10)$ for pessimism, loss of pleasure, and suicidal thoughts.

\section{Discussion}

Despite its prevalence and importance, depression remains substantially under-recognized in medical settings

Table 1. Socio-demographic characteristics and BDI-II scores of HIV uninfected caregiver spouses and HIV uninfected participants in Pune, India.

\begin{tabular}{|c|c|c|c|}
\hline Characteristics & HIV uninfected caregiver spouses $(n=55)$ & HIV uninfected participants $(n=63)$ & $p$ value \\
\hline \multicolumn{4}{|c|}{ Socio-demographic characteristics } \\
\hline${ }^{*}$ Age (mean, SD) & $34.27(7.41)$ & $33.16(6.23)$ & 0.491 \\
\hline Gender (n, female\%) & $31(56.4 \%)$ & $38(60.3 \%)$ & 0.664 \\
\hline Employment (n, \%) & $40(72.72 \%)$ & $51(80.95 \%)$ & 0.289 \\
\hline "Education (mean, SD) & $6.73(4.29)$ & $7.76(3.47)$ & 0.218 \\
\hline \multicolumn{4}{|c|}{ BDI-II scores } \\
\hline *Fast score (mean, SD) & $1.92(2.29)$ & $1(1.82)$ & 0.002 \\
\hline${ }^{*}$ Total score (mean, SD) & $5.25(6.42)$ & $3.03(4.36)$ & 0.029 \\
\hline Total score > 13: (n, \%) & $3(4.8 \%)$ & $7(12.7 \%)$ & 0.12 \\
\hline
\end{tabular}

"Mann-Whitney U Test. 
Table 2. Subscale scores on BDI-II of HIV uninfected caregiver spouses and HIV uninfected participants in Pune, India.

\begin{tabular}{|c|c|c|c|}
\hline Characteristics & HIV uninfected caregiver spouses n (\%) & HIV uninfected participants n (\%) & $p$ value \\
\hline Sadness & $18(32.7)$ & $10(15.9)$ & 0.032 \\
\hline Pessimism & $15(27.3)$ & $9(14.3)$ & 0.080 \\
\hline Past failure & $13(23.6)$ & $11(17.5)$ & 0.406 \\
\hline Loss of pleasure & $16(29.1)$ & $10(15.9)$ & 0.084 \\
\hline Guilty feelings & $7(12.7)$ & $14(22.2)$ & 0.179 \\
\hline Punishment feelings & $7(12.7)$ & $1(1.6)$ & 0.024 \\
\hline Self-dislike & $4(7.3)$ & $3(4.8)$ & 0.704 \\
\hline Self-criticalness & $10(18.2)$ & $6(9.5)$ & 0.171 \\
\hline Suicidal thoughts or wishes & $3(5.5)$ & $0(0)$ & 0.098 \\
\hline Crying & $13(23.6)$ & $6(9.5)$ & 0.037 \\
\hline Agitation & $12(21.8)$ & $10(16.1)$ & 0.432 \\
\hline Loss of interest & $10(18.2)$ & $6(9.5)$ & 0.171 \\
\hline Indecisiveness & $5(9.1)$ & $4(6.3)$ & 0.732 \\
\hline Worthlessness & $3(5.6)$ & $3(4.8)$ & 0.846 \\
\hline Loss of energy & $10(18.2)$ & $9(14.3)$ & 0.566 \\
\hline Changes in sleeping pattern & $9(16.4)$ & $10(15.9)$ & 0.942 \\
\hline Irritability & $15(27.3)$ & $16(25.4)$ & 0.817 \\
\hline Changes in appetite & $7(12.7)$ & $8(12.7)$ & 0.996 \\
\hline Concentration difficulty & $6(10.9)$ & $3(4.8)$ & 0.301 \\
\hline Tiredness or fatigue & $8(14.5)$ & $7(11.1)$ & 0.576 \\
\hline Loss of interest in sex & $16(29.1)$ & $12(19.0)$ & 0.201 \\
\hline
\end{tabular}

[22] and it has been reported that in the primary care setting depression does not get diagnosed in about 50\% patients [23] [24]. This scenario largely reflects clinic attendees and is expected to be equally low or lower for the caregivers of patients. This is because they are struggling with different kinds of stresses resulting from managing the chronic disease of their partners, stigma and discrimination and financial difficulties faced by the family [9]-[15]. It has been reported that the patients' illness symptoms, negative mood, and need for emotional support or physical assistance are often taxing to close family members [25]. It has also been reported that the patients' close family members may experience poorer psychological well-being, relationship issues with the patient, care giving burden, and poorer physical health [26]. The majority of studies evaluating depressive symptoms in caregivers of HIV seropositive spouses have been conducted in western countries, and to the best of our knowledge, this is the first study focused on the caregivers' emotional status in India.

In this study, we report symptoms related to depression in HIV uninfected caregiver spouses by comparing them with another group of HIV uninfected individuals with similar age, gender, occupation and education background from the general community.

The total score on BDI-II was higher in the HIV uninfected caregiver spouses as compared to the others. This is suggestive of the depressive psychological state of the caregiver spouses of HIV infected individuals. In majority items on subscale of BDI-II, though the caregiver spouses have scored higher than the comparison group, the differences in scores are statistically significant only with respect to three items, namely sadness, punishment feelings and crying. The first five ranked concerns by the caregiver spouses were sadness, loss of interest in sex, loss of pleasure, pessimism and irritability. These findings highlight and emphasize the need to address depres- 
sion among the caregivers. Of note, three individuals in the caregiver group endorsed mild suicidal ideation ("I have thoughts of killing myself, but I would not carry them out”) suggesting that clinicians should be cognizant of such issues. In general, the overall depressive symptoms reported by caregivers of HIV infected spouses were low.

The analysis has a limitation. The number of participants is less and hence the findings are not generalizable. The implication of study findings is that the clinicians should evaluate the caregiver spouses of HIV infected individuals for evidence of depression, as they play key role in providing care and support to the infected individuals. Designing and implementing appropriate interventions to provide counseling to spouses may help them to prevent occurrence of depression or develop coping skills to manage it. This may help them in taking better care of their HIV infected partners.

\section{Acknowledgements}

This research was supported by NIMH R01 MH78748 NeuroAIDS in India (Dr. Marcotte, P.I.) and P30 MH62512 HIV Neurobehavioral Research Center (Dr. Grant, P.I.).

\section{References}

[1] Chandra, P.S., Desai, G. and Ranjan, S. (2005) HIV \& Psychiatric Disorders. Indian Journal of Medical Research, 121, 451-467.

[2] Summers, J., Zisook, S., Atkinson, J.H., Sciolla, A., Whitehall, W., Brown, S., et al. (1995) Psychiatric Morbidity Associated with Acquired Immunodeficiency Syndrome-Related Grief Resolution. Journal of Nervous and Mental Disease, 183, 384-389. http://dx.doi.org/10.1097/00005053-199506000-00006

[3] Chandra, P.S. (2002) Psychosocial and Sexual Adjustment among Persons Living with HIV. National Institute of Mental Health and Neurosciences, Bangalore, 56-58.

[4] Perkins, D.O., Stein, R.A., Golden, R.N., Murphy, C., Naftolowitz, D. and Evans, D.L. (1994) Mood Disorders in HIV Infection: Prevalence and Risk Factors in a Non Epicenter of the AIDS Epidemic. American Journal of Psychiatry, 15, 233-236.

[5] Ciesla, J.A. and Roberts, J.E. (2001) Meta-Analysis of Relationship between HIV Infection and Risk of Depressive Disorders. American Journal of Psychiatry, 158, 725-730. http://dx.doi.org/10.1176/appi.ajp.158.5.725

[6] Chandra, P.S., Ravi, V. and Desai, A. (1998) Anxiety and Depression among HIV-Infected Heterosexuals-A Report from India. Journal of Psychosomatic Research, 45, 401-409. http://dx.doi.org/10.1016/S0022-3999(98)00028-2

[7] Sarna, A., Gupta, I., Pujari, S., Sengar, A.K., Garg, R. and Weiss, E. (2006) Examining Adherence and Sexual Behavior among Patients on Antiretroviral Therapy in India. Horizons Final Report.

[8] Sarna, A., Pujari, S., Sengar, A.K., Garg, R., Gupta, I. and Dam, J. (2008) Adherence to Antiretroviral Therapy \& Its Determinants amongst HIV Patients in India. Indian Journal of Medical Research, 127, 28-36.

[9] Engler, P., Anderson, B., Herman, D., Bishop, D., Miller, I., Pirraglia, P., et al. (2006) Coping and Burden among Informal HIV Caregivers. Psychosomatic Medicine, 68, 985-992. http://dx.doi.org/10.1097/01.psy.0000245901.82935.cb

[10] Flaskerud, J.H. and Tabora, B. (1997) Health Problems of Low-Income Female Caregivers of Adults with HIV/AIDS. Heath Care for Women International, 19, 23-26. http://dx.doi.org/10.1080/073993398246557

[11] Folkman, S., Chesney, M.A., Cooke, M., Boccellari, A. and Collette, L. (1994) Caregiver Burden in HIV-Positive and HIV-Partners of Men with AIDS. Journal of Consulting and Clinical Psychology, 62, 746-756. http://dx.doi.org/10.1037/0022-006X.62.4.746

[12] Moskowitz, J.T., Folkman, S., Collette, L. and Vittinghoff, E. (1996) Coping and Mood during AIDS-Related Caregiving and Bereavement. Annals of Behavioral Medicine, 18, 49-57. http://dx.doi.org/10.1007/BF02903939

[13] Miller, I.W., Bishop, D.S. and Stein, M.D. (2007) Relationship Quality among HIV Patients and Their Caregivers. AIDS Care, 19, 203-211. http://dx.doi.org/10.1080/09540120600624278

[14] Silverman, D.C. (1992) Psychosocial Impact of HIV-Related Caregiving on Health Problems: A Review and Recommendations for the Role of Psychiatry. American Journal of Psychiatry, 150, 705-712.

[15] Abasiubong, F., Bassey, E.A., Ogunsemi, O.O. and Udobang, J.A. (2011) Assessing the Psychological Well-Being of Caregivers of People Living with HIV/AIDS in Niger Delta Region, Nigeria. AIDS Care, 23, 494-500. http://dx.doi.org/10.1080/09540121.2010.516340

[16] Savard, J., Laberge, B., Gauthier, J.G. and Bergeron, M.G. (1999) Screening Clinical Depression in HIV-Seropositive Patients Using the Hospital Anxiety and Depression Scale. AIDS and Behavior, 3, 167-175. 
http://dx.doi.org/10.1023/A:1025444225120

[17] Affonso, D., Anindya, K., Horrowitz, J. and Mayberry, L. (2000) An International Study Exploring Levels of Postpartum Depressive Symptomatology. Journal of Psychosomatic Disorder, 49, 207-216. http://dx.doi.org/10.1016/S0022-3999(00)00176-8

[18] Basker, M., Moses, P.D., Russell, S. and Russell, P.S. (2007) The Psychometric Properties of Beck Depression Inventory for Adolescent Depression in a Primary-Care Paediatric Setting in India. Child and Adolescent Psychiatry and Mental Health, 1, 8. http://dx.doi.org/10.1186/1753-2000-1-8

[19] Kulkarni, H.S., Kulkarni, K.R., Mallampalli, A., Karnad, D.R., Parkar, S.R. and Guntupalli, K.K. (2008) Comparison of Anxiety, Depression and Post-Traumatic Stress Disorder in the Relatives of Critically Ill Patients in an American and Indian Public Hospital. Chest, 134.

[20] Beck, A.T., Steer, R.A. and Brown, G.K. (1996) BDI-II Manual. The Psychological Corporation, London.

[21] Beck, A.T., Steer, R.A. and Brown, G.K. (2000) BDI-II Fast Screen for Medical Patients Manual. The Psychological Corporation, London.

[22] Huffman, J.C., Smith, F.A., Blais, M.A., Beiser, M.E., Januzzi, J.L. and Fricchione, G.L. (2006) Rapid Screening for Major Depression in Post-Myocardial Infarction Patients: An Investigation Using Beck Depression II Items. Heart, 92, 1656-1660. http://dx.doi.org/10.1136/hrt.2005.087213

[23] Simon, G.E. and VonKorff, M. (1995) Recognition, Management and Outcomes of Depression in Primary Care. Archives of Family Medicine, 4, 99-105. http://dx.doi.org/10.1001/archfami.4.2.99

[24] Simon, G.E., Goldberg, D. and Tiemens, B.G. (1999) Outcomes of Recognized and Unrecognized Depression in an International Primary Care Study. General Hospital Psychiatry, 21, 97-105. http://dx.doi.org/10.1016/S0163-8343(98)00072-3

[25] Akamatsu, T.J., Crowther, J.H., Hobfoll, S.E. and Stephens, A.P. (1992) Family Health Psychology. Taylor \& Francis, Bristol.

[26] Schulz, R., O’Brien, A.T., Bookwala, J. and Fleissner, K. (1995) Psychiatric and Physical Morbidity Effects of Dementia Caregiving: Prevalence, Correlates, and Causes. The Gerontologist, 35, 771-791. http://dx.doi.org/10.1093/geront/35.6.771 
Scientific Research Publishing (SCIRP) is one of the largest Open Access journal publishers. It is currently publishing more than 200 open access, online, peer-reviewed journals covering a wide range of academic disciplines. SCIRP serves the worldwide academic communities and contributes to the progress and application of science with its publication.

Other selected journals from SCIRP are listed as below. Submit your manuscript to us via either submit@scirp.org or Online Submission Portal.
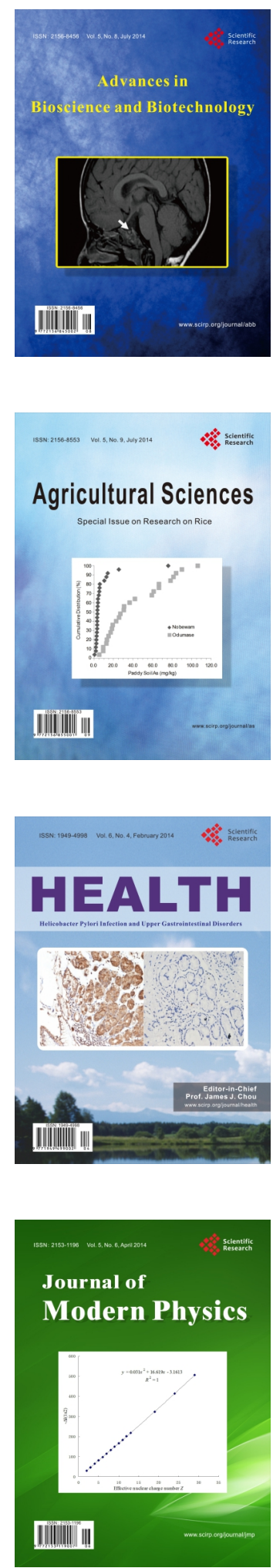
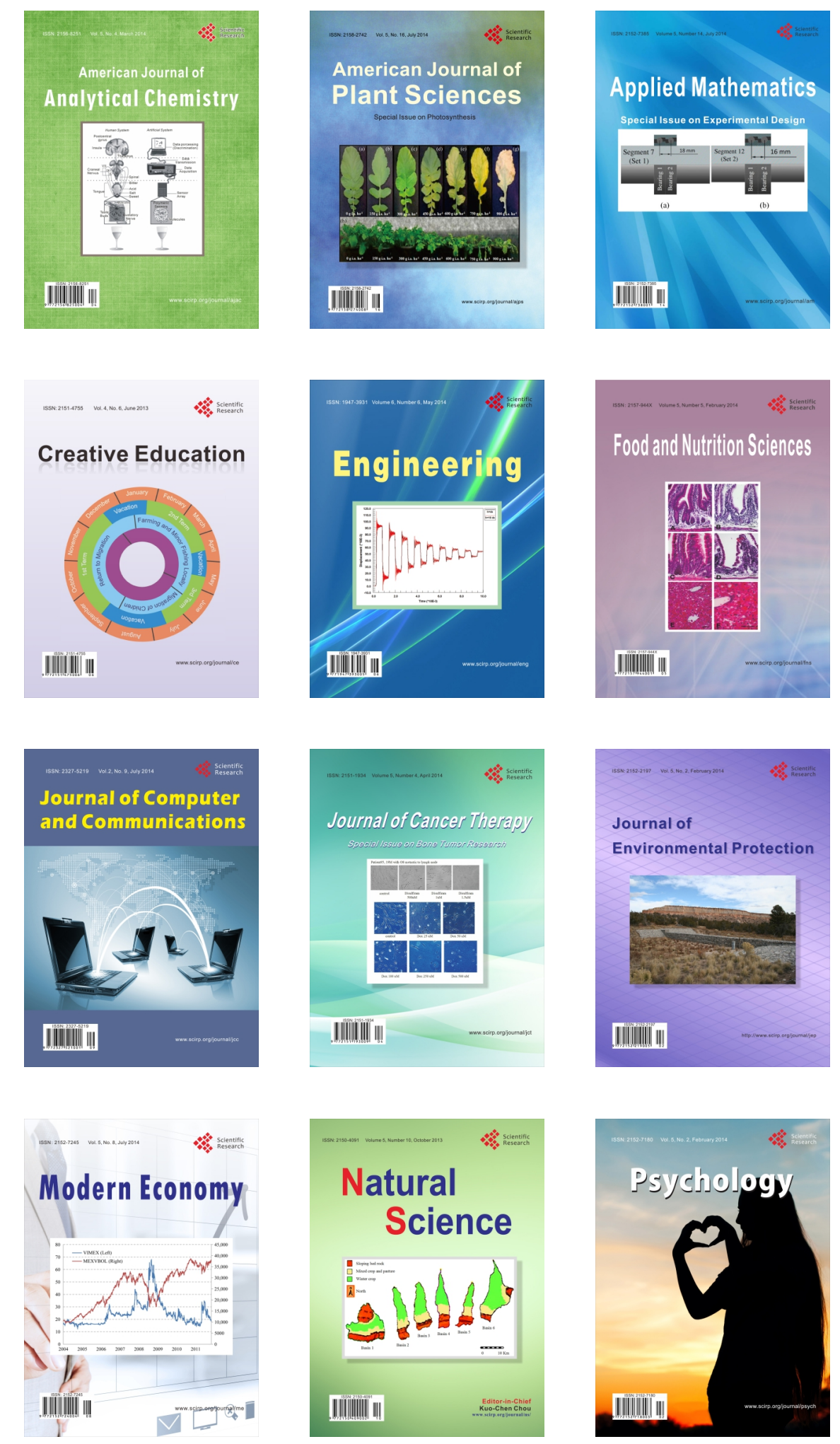